\title{
COMPOSIÇÃO VOLÁTIL DOS DEFEITOS INTRÍNSECOS DO CAFÉ POR CG/EM-HEADSPACE
}

\author{
Raquel D. C. C. Bandeira, Aline T. Toci, Luiz C. Trugo e Adriana Farah* \\ Departamento de Bioquímica, Instituto de Química, Universidade Federal do Rio de Janeiro, Ilha do Fundão, 21949-900 \\ Rio de Janeiro - RJ, Brasil
}

Recebido em 23/1/08; aceito em 29/9/08; publicado na web em 5/2/09

\begin{abstract}
VOLATILE COMPOSITION OF INTRINSIC DEFECTIVE COFFEE BEANS BY GC/MS-HEADSPACE. About $20 \%$ of Brazilian raw coffee production is considered inappropriate for exportation. Consequently, these beans are incorporated to good quality beans in the Brazilian market. This by-product of coffee industry is called PVA due to the presence of black (P), green (V) and sour (A) defective beans which are known to contribute considerably for cup quality decrease. Data on the volatile composition of Brazilian defective coffee beans are scarce. In this study, we evaluated the volatile composition of immature, black-immature, black defective beans and PVA compared to good quality beans. Potential defective beans markers were identified.
\end{abstract}

Keywords: defective coffee beans; coffee flavor; volatile compounds.

\section{INTRODUÇÃO}

O café é o segundo produto mais comercializado do mundo, depois do petróleo. ${ }^{1}$ As duas espécies de café economicamente mais importantes são Coffea arabica e Coffea canephora. Estas possuem características físico-químicas bem diferenciadas, que acabam por produzir bebidas com características sensoriais distintas. A espécie Coffea arabica é de grande significado econômico para as Américas e demais regiões que a cultivam. Seu produto é de qualidade superior e de maior aceitação em todos os mercados. Atualmente, esta espécie é responsável por cerca de $64 \%$ da produção mundial de café.

O Brasil é o maior produtor e exportador mundial de grãos de café, sendo também atualmente o segundo maior consumidor. ${ }^{2}$ Devido ao grande volume de produção, o Brasil adota preferencialmente técnicas de colheita como a derriça e a colheita mecânica, nas quais todos os frutos são colhidos de uma só vez no pano ou no chão. O cafeeiro possui várias floradas e por isso encontramos, em um mesmo período, frutos com diferentes graus de maturação. Conseqüentemente, frutos verdes, maduros e passados são colhidos. Por estas razões, cerca de $20 \%$ da produção brasileira (mais de 8 milhões de sacas) correspondem a grãos defeituosos que, por serem considerados impróprios para exportação, são incorporados no mercado interno. ${ }^{3}$

O café é oficialmente qualificado pela ABIC (Associação Brasileira das Indústrias de Café) por critérios como tipo de colheita, tipo de beneficiamento, tamanho e cor dos grãos, safra, presença de defeitos, entre outras. Os defeitos, por sua vez, são classificados como extrínsecos e intrínsecos. ${ }^{4}$ Defeitos extrínsecos são decorrentes de impurezas incorporadas ao café durante a colheita, como pedras, gravetos, cascas, cocos, entre outros. Defeitos intrínsecos são decorrentes de grãos alterados devido à imperfeição de processos agrícolas, modificações fisiológicas ou genéticas do fruto, ou por práticas de beneficiamento inadequadas. Exemplos de defeitos intrínsecos são: verde, ardido, preto, preto-verde, stinker, brocado, mal-granado, concha, quebrado, entre outros. Grãos verdes são originados pela colheita de grãos ainda não amadurecidos e causam o aumento da adstringência da bebida. ${ }^{5-7}$ Grãos ardidos podem ser gerados por deficiências hídricas do cafeeiro durante a formação do fruto, ou por fermentação indevida de grãos

*e-mail: afarah@iq.ufrj.br

†n Memoriam verdes ou maduros ${ }^{6,7}$ De acordo com Pimenta, ${ }^{6}$ grãos ardidos podem originar também grãos pretos. Todavia, grãos pretos são mais comumente originados pela colheita no pé ou no chão de grãos passados do ponto de maturação, sujeitos a fermentações pela ação microbiana. ${ }^{8,9}$ De acordo com Bee e colaboradores, ${ }^{7}$ grãos pretos podem também ser originados por deficiência de carboidratos do cafeeiro decorrentes de práticas agrícolas inadequadas. Grãos preto-verdes são originados pela exposição do defeito verde a altas temperaturas. ${ }^{7}$ Por outro lado, de acordo com Teixeira e colaboradores, ${ }^{10}$ grãos preto-verdes podem ser derivados de processos inadequados de secagem dos grãos verdes. Os grãos preto-verdes podem ser diferenciados dos grãos fermentados pela película luminosa e aderente na sua superfície. Os grãos pretoverdes e verdes são considerados sérios defeitos por prejudicarem muito a qualidade final da bebida. ${ }^{8}{ }^{11}$ Grãos stinker são originados por fermentação excessiva dos grãos sadios. ${ }^{7}$ Estes defeitos possuem uma aparência normal, não sendo detectados visualmente. São somente detectados nos grãos por métodos químicos ou por fluorescência. ${ }^{7}$ No entanto, são mais comumente detectados na prova de xícara, por apresentarem características sensoriais extremamente desagradáveis. ${ }^{7}$ O conjunto de grãos defeituosos é conhecido como PVA, já que os defeitos pretos, verdes e ardidos são os mais comuns e de grande significância para a qualidade da bebida.

A presença de grãos defeituosos afeta negativamente a qualidade final da bebida ${ }^{10,11}$ e na tentativa de identificar os compostos responsáveis pela queda de qualidade há um crescente interesse pelo conhecimento da composição química desses defeitos. ${ }^{12,13}$ Todavia, pouco ainda se sabe a respeito de sua composição volátil, principalmente devido à sua complexidade e à dificuldade de se detectar todos os compostos existentes através de uma só metodologia análitica. 2-metil-isobutanol, 2,4,6-tricloroanisol, geosmin, 2-metoxi-3isopropilpirazina e 2-metoxi-3-isobutilpirazina foram identificados como compostos voláteis responsáveis por notas negativas no café, ${ }^{14-16}$ mas nenhum destes compostos foi identificado como proveniente de defeitos característicos da classificação brasileira. Já os compostos etil-isobutanoato, isoamil-acetato, isobutil-acetato, etil-butanoato, 2-metil-etil-butanoato, $n$-hexil-acetato, 2-acetilpirazina e $\beta$-linalol foram identificados em grãos stinker quando comparandos aos grãos saudáveis. ${ }^{17}$ Em um recente estudo, Toci e Farah ${ }^{18}$ também indicaram alguns compostos como potenciais marcadores de defeitos crus e torrados, mais especificamente a 2-metilpirazina e o 2-furilmetanol 
nos grãos preto-verdes crus, a butirolactona e o benzaldeído nos grãos ardidos crus e a 2,3,5,6-tetrametilpirazina em defeitos inespecíficos. No conjunto de defeitos torrados (PVA) foram identificados: pirazina, 2,3-butanodiol meso, 2-metil-5-(1-propenil) pirazina, ácido hexanóico, 4-etil-guaiacol e sulfito de isopropil $p$-cresol como potenciais marcadores de defeitos.

Atualmente, a realidade do mercado interno é que existem blends comerciais com mais de $50 \%$ de PVA, embora a ABIC recomende a inclusão de no máximo $20 \%$ de defeitos. ${ }^{19}$ Além do prejuízo à qualidade da bebida, as implicações desses grãos defeituosos à saúde não são completamente conhecidas e, por esta razão, existe um consentimento geral pela diminuição da incorporação desses grãos nos blends de cafés comerciais, o que levou, entre outras razões, à criação do "Programa de Qualidade do Café" (PQC), lançado pela ABIC em 2004, que consiste não somente no controle da qualidade dos blends comerciais, mas também na educação do torrefador e do consumidor. Daí o grande interesse na caracterização desses grãos e na identificação de compostos que possam ser usados futuramente como marcadores da presença de defeitos no café. Sendo assim, o objetivo deste estudo foi a caracterização da composição volátil dos principais defeitos intrínsecos de cafés comumente comercializados no Brasil, comparando-os com os grãos sadios.

\section{PARTE EXPERIMENTAL}

\section{Desenho experimental}

A caracterização da composição volátil de todas as amostras foi realizada em três etapas. A primeira teve como objetivo a obtenção dos perfis cromatográficos das amostras investigadas, utilizando-se um cromatógrafo a gás acoplado ao headspace automático. A segunda foi a realização da análise estatística multivariada de componentes principais (ACP), que teve como objetivo agrupar as diferentes amostras de acordo com o perfil de cada uma e selecionar os compostos voláteis mais relevantes estatisticamente, em termos de abundância e prevalência. A terceira etapa, utilizando o cromatógrafo a gás acoplado ao espectrômetro de massa, teve como objetivo a identificação dos principais compostos selecionados na segunda etapa, bem como a tentativa de identificação adicional do maior número possível de compostos nos diferentes grupos de amostras.

\section{Matéria-prima}

As espécies Coffea arabica e Coffea canephora foram utilizadas neste estudo, sendo analisadas as seguintes amostras: grãos sadios de cada espécie (controles); os defeitos verde, preto-verde e preto da espécie C. arabica; o defeito preto da espécie C. canephora e o conjunto de defeitos PVA da espécie $C$. arabica.

$220 \mathrm{~g}$ de cada amostra de café foram torrados em um torrador elétrico do tipo pipoqueira (Cael Ltda., Brasil), a uma temperatura média de $205^{\circ} \mathrm{C}$, por 12 e $20 \mathrm{~min}$, resultando em torras classificadas de acordo com o sistema colorimétrico "Roast Color Classification System" (AGTRON - SCAA, USA, 1995) como moderadamente escura \#45 e escura \#35, comumente consumidas no Brasil. As amostras foram moídas em granulometria fina de $0,45 \mathrm{~mm}$.

\section{Extração dos voláteis}

0,5 g de cada amostra recém moída (mesmo dia) foi pesado em vial de headspace de $20 \mathrm{~mL}$, sendo este devidamente selado. O vial foi aquecido em banho-maria a $100{ }^{\circ} \mathrm{C}$ por $12 \mathrm{~min}$. Após este período, uma seringa Gas Tight (Hamilton, USA), previamente condicionada em estufa a $105{ }^{\circ} \mathrm{C}$, foi inserida no vial e o volume de $0,8 \mathrm{~mL}$ foi utilizado para análises em CG/DIC (cromatógrafo a gás com detector de ionização de chamas) e 1,0 mL para análise em CG/EM (cromatógrafo a gás acoplado ao espectrômetro de massas). O procedimento foi realizado separadamente para as análises de CG/DIC e CG/EM.

\section{Análise por cromatografia a gás com detector de ionização de chamas (CG/DIC)}

As análises foram realizadas em cromatógrafo a gás acoplado ao headspace automático CG17A/HSS-4A (Shimadzu, Kyoto, Japão). A coluna Supelcowax-10 (30 m X 0,53 mm X 1,0 $\mu \mathrm{m})$ foi utilizada. As condições cromatográficas foram: sistema de injeção - splitless; temperatura do injetor $-200^{\circ} \mathrm{C}$; rampa de eluição $-40^{\circ} \mathrm{C}(5 \mathrm{~min})$ para $160^{\circ} \mathrm{C}$ a $3{ }^{\circ} \mathrm{C} / \mathrm{min}$; detector - DIC; temperatura do detector $-250{ }^{\circ} \mathrm{C}$; gás carreador - hélio; fluxo - $0,2 \mathrm{~mL} / \mathrm{min}^{20}$

\section{Análise por cromatografia a gás acoplada ao espectrômetro de massas (CG/EM)}

As análises foram realizadas em cromatógrafo da Shimadzu CGMS QP5050 (Kyoto, Japão). Uma coluna Omegawax ${ }^{\mathrm{TM}} 250$ (30 m X 0,25 mm X 0,25 $\mu \mathrm{m}$ ) foi utilizada. As condições cromatográficas foram: sistema de injeção - split; razão de split - 1:10; temperatura do injetor $-200{ }^{\circ} \mathrm{C}$; temperatura da interface $-230{ }^{\circ} \mathrm{C}$; rampa de eluição - $40^{\circ} \mathrm{C}$ (3 min) para $160{ }^{\circ} \mathrm{C} \mathrm{a} 3{ }^{\circ} \mathrm{C} / \mathrm{min}$; detector - quadrupolo; gás carreador - hélio; fluxo - 0,2 $\mathrm{mL} / \mathrm{min}$; detector - quadrupolo; voltagem do detector $-2,2 \mathrm{Kv}$. A aquisição dos espectros de massa foi de 40-300 razão carga-massa $(\mathrm{m} / \mathrm{z}){ }^{20}$

\section{Processamento dos dados}

O cromatograma de íons totais foi processado utilizando-se o software CLASS-5000 (Shimadzu, version 2.0, Kyoto, Japão), e a biblioteca virtual de espectros NIST-62. Índices de Kovats e padrões (2-butanona, piridina, 2-metilpirazina, 2-furilmetanol, etanal, ácido etanóico - Sigma Aldrich, Steinheim, Alemanha). A análise estatística foi realizada no programa Principal Component Analysis Program (SPSS, version 10.0, Chicago, USA).

\section{RESULTADOS E DISCUSSÃO}

\section{Análise por cromatografia a gás}

Os perfis cromatográficos obtidos a partir das amostras cruas foram de menor complexidade quando comparados às amostras torradas. De modo geral, através de inúmeras reações químicas, entre elas Strecker, Maillard e pirólise, ${ }^{21}$ o processo de torração ocasionou o enriquecimento no perfil de voláteis das amostras, formando uma série de compostos responsáveis pelo aroma característico do café.

As amostras controle de $C$. arabica e $C$. canephora cruas não apresentaram diferença qualitativa na observação visual dos perfis cromatográficos, havendo somente diferença nas intensidades dos compostos encontrados. No entanto, as amostras torradas, de ambas espécies, apresentaram perfis cromatográficos diferenciados, provavelmente devido à diferença na composição dos compostos precursores de voláteis entre as espécies.

As amostras de defeitos verde e preto-verde, tanto torradas como cruas, apresentaram perfis cromatográficos semelhantes entre si. Nos defeitos preto $C$. arabica e $C$. canephora crus também não houve diferenças qualitativas entre os cromatogramas. Porém, o aumento do grau de torra intensificou a distinção entre as espécies. O perfil cromatográfico da amostra da mistura de defeitos PVA cru se assemelhou muito aos dos defeitos preto $C$. arabica e $C$. canephora. Nas amostras 
de PVA torradas, este efeito também foi observado nos dois graus de torra investigados, o que sugere uma significativa contribuição do defeito preto para a composição volátil do PVA.

\section{Análise dos componentes principais (ACP)}

A Figura 1 é a representação gráfica da primeira e segunda componente da ACP realizada entre os diferentes defeitos do café e a mistura PVA que, no seu conjunto, justificam $50 \%$ da variância dos dados. A análise estatística reduziu o número de variáveis originais a 5 componentes principais (CPs) que explicam 93\% da variância das variáveis originais

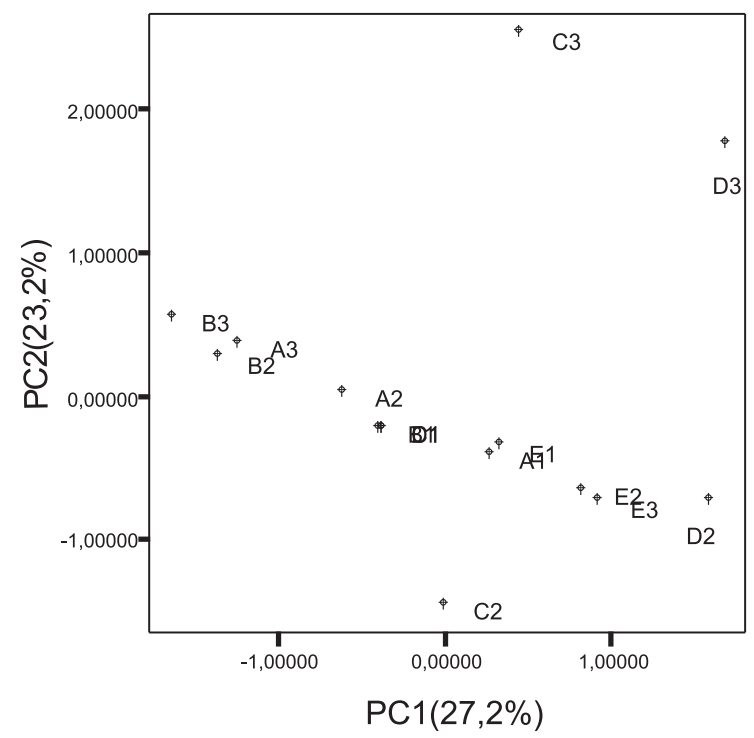

Figura 1. Interação bidimensional entre os diferentes defeitos intrínsecos do café e a mistura PVA. Defeitos analisados: A - Preto-verde C. arabica; $B$ - Verde C. arabica; C - Preto C. arabica; D - PVA (mistura de defeitos); E- Preto C. canephora. Torras: 1-amostra crua, 2-torra moderadamente escura, 3- escura

Apesar de serem provenientes de defeitos tão diferentes, as amostras cruas situaram-se bem próximas umas das outras (Figura 2). No entanto, a torração produziu variações gradativas na composição volátil dos diferentes defeitos, produzindo um distanciamento em relação ao posicionamento inicial. $\mathrm{O}$ defeito verde (B) assemelhouse em alguns aspectos ao preto-verde (A), o que é consistente com a análise visual dos cromatogramas feita anteriormente e com o fato do defeito preto-verde ser proveniente de frutos imaturos. ${ }^{7}$ Os defeitos pretos crus, de ambas espécies $(\mathrm{C}, \mathrm{E})$ localizaram-se próximos entre si, sugerindo que existem compostos semelhantes entre as duas espécies desse defeito. Segundo Franca e colaboradores,$^{13}$ o defeito preto tem características distintas quando comparado aos demais defeitos. Com o aumento de grau de torra, os defeitos pretos ficaram mais distintos entre si. O defeito preto C. canephora (E) foi o que apresentou as características mais próximas do PVA (D).

As variáveis selecionadas nas amostras avaliadas foram identificadas como os seguintes compostos: 2-metilpirazina (CP1), 2-furilmetanol (CP2), 2-butanona, piridina e 3-hidroxi-2-butanona, em ordem de importância. A Tabela 1 apresenta a identificação dos compostos selecionados por espectrometria de massas (EM), índice de Kovats (IK) e padrões.

De acordo com a literatura, a maioria dos componentes principais identificados são potentes odorantes para o café..$^{15,17,22,23} \mathrm{~A}$ 3-hidroxi2-butanona está associada a um off-flavour em grãos verdes e pode ser resultante da fermentação produzida por Enterobacterias. ${ }^{15}$ Seu odor
Tabela 1. Identificação dos principais compostos por espectrometria de massas (EM), índices de Kovats (IK) e padrões

\begin{tabular}{cccc}
\hline $\mathrm{n}^{\circ}$ & T.R. & IK Calculado & Compostos $^{1,3}$ \\
\hline 1 & 4,088 & - & 2-butanona $^{1,3}$ \\
2 & 12,358 & 1177 & piridina $^{1,2,3}$ \\
3 & 15,921 & 1263 & 2-metil-pirazina $^{1,2,3}$ \\
4 & 16,854 & 1282 & 3-hidroxi-2-butanona $^{1,2}$ \\
5 & 33,204 & 1646 & 2-furilmetanol $^{1,2,3}$ \\
\hline
\end{tabular}

T.R.- Tempo de Retenção; 1-EM; 2-IK; 3-Padrão.

é descrito como creme de manteiga, penetrante, químico, tornandose agradável quando muito diluído. ${ }^{22} \mathrm{~A}$ 2-metilpirazina possui odor amendoado, torrado e achocolatado, quando diluído ${ }^{22,23}$ e é descrita como desagradável por Guyot e colaboradores. ${ }^{17} \mathrm{O}$ odor do 2-furilmetanol é descrito como leve, caramelado e de óleo morno, estando correlacionado com notas indesejadas de queimado e amanteigado em torras muito escuras. ${ }^{22} \mathrm{O}$ odor da piridina é descrito como pungente e penetrante..$^{22}$

\section{Identificação dos compostos voláteis por CG-EM}

Os compostos descritos a seguir foram identificados somente pela biblioteca virtual de espectros Nist-62, utilizando-se um critério de segurança de $90 \%$ de confiabilidade.

\section{Grãos crus}

Um total de 15 compostos voláteis foi encontrado nas amostras cruas de café (Tabela 2), sendo 4 álcoois, 4 aldeídos, 3 ésteres, 1 ácido carboxílico, 1 furano, 1 acetona e 1 nitrila.

Comparando as duas amostras controle (Tabela 2), nenhuma diferença qualitativa em relação aos compostos voláteis foi encontrada. A diferenciação entre as duas espécies está nas concentrações relativas dos compostos voláteis. Observa-se também a abundância de compostos alcoólicos, fato este de acordo com a literatura. ${ }^{22,24}$ Comparando os cafés controles com os demais defeitos, observa-se a 2-propanona como composto exclusivo dos cafés controles. Estando esta descrita como levemente etérea e nauseante. ${ }^{22}$

No defeito verde foram encontrados os seguintes compostos exclusivos: dodecanoato de metila, 1-butanol, e 3-metil-1-butanol, revelando o primeiro indício da diferenciação entre defeitos da mesma espécie (Tabela 2). No entanto, como as duas espécies foram provenientes de origens diferentes essa pode ser a causa da diferença. O 1-butanol possui nota alcoólica, e o 3-metil-1-butanol é descrito como picante, penetrante e acre. ${ }^{17}$ Este também foi o defeito mais rico em compostos voláteis, possuindo 11 dos 15 compostos identificados, como também observado por Toci e Farah. ${ }^{18} \mathrm{O}$ composto 2-furilmetanol, presente nos grãos controles, não foi encontrado neste defeito.

No defeito preto-verde foi encontrado o composto 2-metilpropanal, presente exclusivamente neste defeito (Tabela 2). 2-metilpropanal é extremamente difusivo, penetrante, pungente e repulsivo, tornandose em extremas diluições agradável e com notas frutadas e de banana. ${ }^{22}$ Diferentemente dos demais defeitos, a acetonitrila não foi encontrada no defeito preto-verde. Dentre os defeitos estudados, este também foi o único a possuir os compostos etanal e 2-furilmetanol, presentes em ambas as espécies controles.

Nos grãos pretos não foi encontrado nenhum composto exclusivo deste defeito. No entanto, podemos observar uma maior concentração relativa do composto 3-metilbutanal em relação aos demais defeitos (Tabela 2). Tal composto não foi observado nos grãos controles. Outra 
Tabela 2. Identificação dos compostos voláteis nas amostras cruas por espectrometria de massas

\begin{tabular}{|c|c|c|c|c|c|c|c|c|}
\hline \multirow[b]{2}{*}{$n^{\circ}$} & \multirow[b]{2}{*}{ compostos } & \multicolumn{5}{|c|}{ C. arabica } & \multicolumn{2}{|c|}{ C. canephora } \\
\hline & & $\begin{array}{c}\% \text { Controle } \\
\text { (puro) }\end{array}$ & $\%$ Verde & $\%$ Preto-verde & $\%$ Preto & $\%$ PVA & $\begin{array}{c}\% \text { Controle } \\
\text { (puro) }\end{array}$ & $\%$ Preto \\
\hline 1 & etanol & 60,12 & 50,16 & 42,25 & 4,52 & 56,34 & 60,32 & 43,87 \\
\hline 2 & 1-butanol & nd & 1,61 & nd & nd & nd & nd & nd \\
\hline 3 & 3-metilbutanol & nd & 1,87 & nd & nd & nd & nd & nd \\
\hline 4 & 2,3-butanodiol & 9,5 & 2,46 & 0,74 & nd & nd & 10,25 & nd \\
\hline 5 & etanal & 1,52 & nd & 3,4 & nd & 4,97 & 10,81 & nd \\
\hline 6 & 2-metilpropanal & nd & nd & 35,18 & nd & 5,11 & nd & nd \\
\hline 7 & 2-metilbutanal & nd & 15,81 & 4,23 & nd & 5,24 & nd & 4,52 \\
\hline 8 & 3-metilbutanal & nd & nd & 9,16 & 24,72 & 9,9 & nd & 19,24 \\
\hline 9 & acetato de etila & nd & 8,47 & 2,47 & 6,03 & 11,38 & nd & 9,4 \\
\hline 10 & decanoato de etila & nd & 0,94 & nd & nd & nd & nd & nd \\
\hline 11 & dodecanoato de metila & nd & 6,08 & nd & 39,88 & nd & nd & nd \\
\hline 12 & 2-propanona & 1,52 & nd & nd & nd & nd & 1,73 & nd \\
\hline 13 & ácido etanóico (ác. acético) & 8,07 & 3,68 & 1,03 & nd & nd & 7,39 & 8,49 \\
\hline 14 & 2-furilmetanol & 10,88 & nd & 1,54 & nd & nd & 6,62 & nd \\
\hline 15 & etanonitrila (acetonitrila) & 8,31 & 8,92 & nd & 24,83 & 7,06 & 2,83 & 14,47 \\
\hline
\end{tabular}

\% - concentração relativa à área total; -nd- não detectado.

característica destes grãos defeituosos foi a ausência, em ambas as espécies, dos compostos 2-furilmetanol e 2,3-butanodiol, contidos nos grãos controles, e a presença de 2-metilbutanal e 3-metilbutanal não contidos nos grãos controles. Sabe-se que a formação de aldeídos voláteis está associada à oxidação dos alcoóis. ${ }^{17,21}$ Ambos são considerados compostos de impacto para o café, ${ }^{25}$ sendo o odor do 2-metilbutanal descrito como potente e sufocante, mas tolerável quando diluído. ${ }^{22} \mathrm{O}$ odor do 3-metilbutanal, por sua vez, é descrito como fétido, acre e rançoso. ${ }^{17}$

No conjunto de defeitos PVA, foram encontrados vários voláteis presentes tanto nas amostras controles como nos grãos defeituosos (Tabela 2). Porém, observa-se que nem todos os compostos presentes nos grãos defeituosos foram encontrados na mistura, o que pode ser explicado pelos baixos percentuais de cada defeito na mesma.

Alguns compostos foram encontrados em mais de um tipo de defeito, mas não nos grãos controles, como 3-metilbutanal (verde, preto-verde e preto $C$. canephora) e 2-metilbutanal (preto C. arabica, preto $C$. canephora e preto-verde).

\section{Grãos torrados}

Com a torra e conseqüente degradação dos compostos precursores de aroma, a complexidade da fração volátil aumentou, como observado nas Figuras 1a e 1b. Foi encontrado um total de 34 compostos voláteis, sendo os mais abundantes 8 cetonas, 6 aldeídos e 5 pirazinas (Tabela 3).

Não foram observadas diferenças qualitativas entre os grãos controles das duas espécies (Tabela 3). Os compostos etanal e 1-hidroxi-2-propanona foram encontrados somente nestas amostras, em ambas as torras. O etanal confere notas etéreas, de verde, frescor e frutado, já a 1-hidroxi-2-propanona confere notas de pungência e de doce-caramelado. ${ }^{22}$

No defeito verde foi encontrada a 2-pentanona como composto exclusivo (Tabela 3 ). Seu odor é potente e muito difusivo, também possuindo características etéreas e frutadas. ${ }^{22}$ Assim como nos grãos verdes crus, nos grãos verdes torrados verificou-se a maior abundância de compostos voláteis, somando um total de 28 dos 34 identificados nas amostras torradas.

Nos defeitos preto-verdes na torra moderadamente escura, por sua vez, encontramos o 2,3-butanodiol como composto exclusivo (Tabela 3). Podemos enfatizar também o hexanal, encontrado na torra escura deste defeito e também no defeito preto C. arabica. $\mathrm{O}$ hexanal possui importante impacto para o aroma do café, conferindo notas gordurosas e de óleo verde. De acordo com Guyot e colaboradores, ${ }^{17}$ este composto é mais perceptível no defeito Stinker que em grãos saudáveis.

Os compostos pentanal, 1-pentanol e 2-pentilfurano foram exclusivos do defeito preto $C$. arabica, não sendo nem mesmo observado no defeito preto C. canephora (Tabela 3 ). Isso indica uma potencial diferenciação aromática entre defeitos de espécies diferentes. No entanto, é importante que amostras de espécies diferentes, mas de mesma origem, sejam estudadas para confirmar essa diferença entres as espécies. O 1-pentanol confere notas de adstringência, química, e nauseante. ${ }^{22} \mathrm{O} 2$-pentil-furano confere notas de terra, madeira e óleo de anis. ${ }^{22}$ É interessante também ressaltar a diferenciação destas duas espécies na torra moderadamente escura do defeito preto, no qual o $C$. canephora se apresentou rico em cetonas e pirazinas, e o C. arabica apresentou predominantemente furanos. Os furanos são oriundos principalmente da degradação dos glicídios presentes no café, ${ }^{21,26}$ sugerindo que o maior teor de sacarose e glicídios observados nos grãos do C. arábica $^{27,28}$ podem estar influenciando tais níveis destes compostos.

No conjunto de defeitos PVA torrado, obteve-se também o mesmo comportamento observado nos grãos crus, onde foram encontrados vários voláteis presentes tanto nos grãos controles como nos grãos defeituosos (Tabela 3), o que faz sentido, já que esta mistura é composta tanto de grãos controles quanto de defeituosos.

Alguns compostos foram encontrados somente nos grãos defeituosos, não estando presentes nos grãos controles, como 1-hidroxi-2butanona, 2-metilpropanal, hexanal, decanoato de etila e dodecanoato de metila, presentes somente nos defeitos C. arabica. Já o pirrol foi encontrado em todos os defeitos estudados. 
Tabela 3. Identificação dos compostos voláteis nas amostras torradas por espectrometria de massas

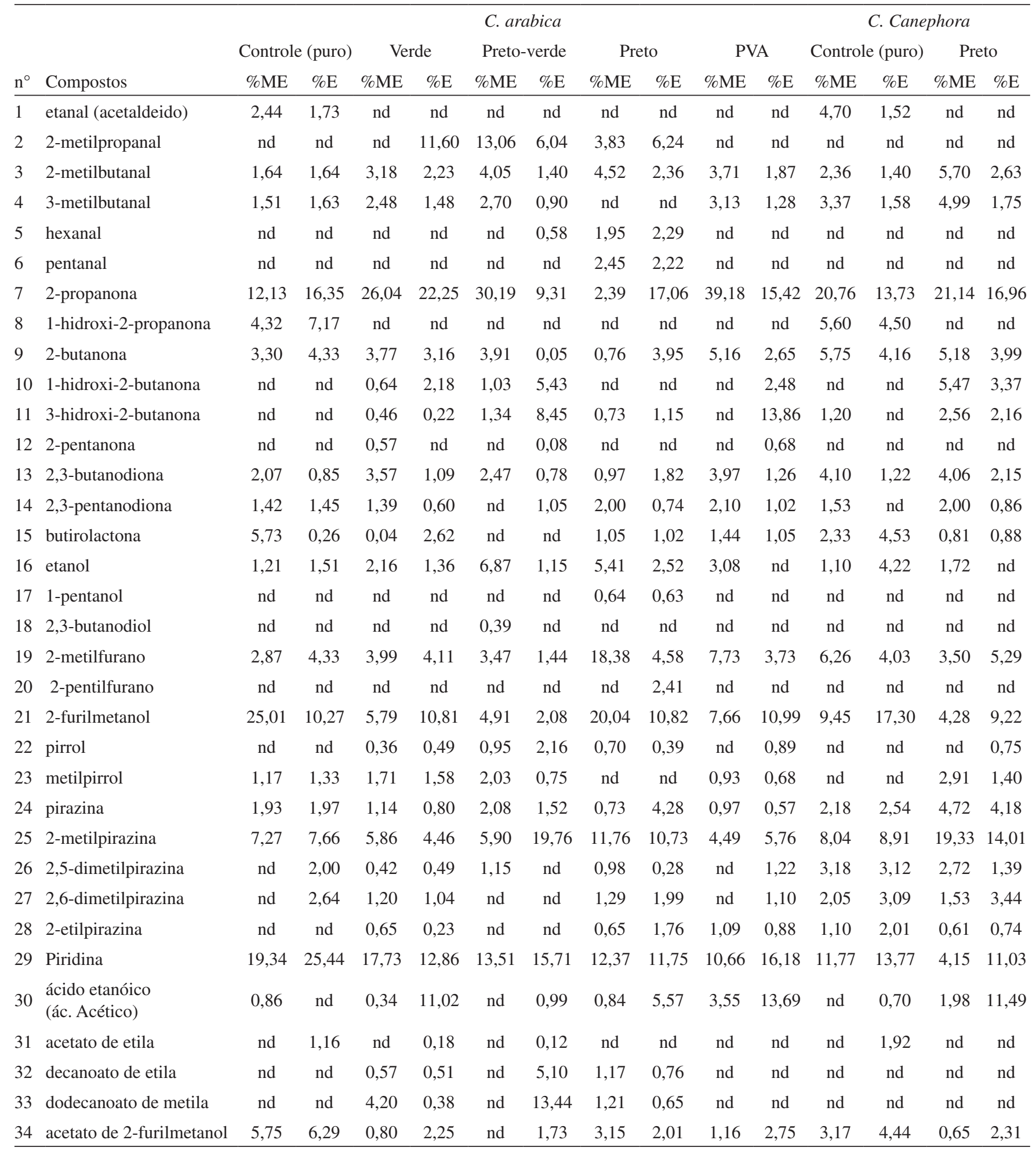

$\%$ - concentração relativa à área total; nd - não detectado; Torras: $\mathrm{ME}=$ moderadamente escura, $\mathrm{E}=$ escura.

De forma geral, existem indícios de que os compostos exclusivos dos defeitos sejam responsáveis pelas notas prejudiciais ao aroma, de acordo com as características aromáticas encontradas na literatura. ${ }^{17,22,23,25}$ Nota-se também que os compostos voláteis refletiram as origens dos defeitos, no que diz respeito aos processos sofridos por cada grão como, por exemplo, a presença de aldeídos nos defeitos preto-verde e preto, revelando que tais grãos sofreram processos fermentativos, devido ao calor ou ao tempo de colheita.
O aumento do grau de torra não modificou qualitativamente os compostos voláteis, com exceção do defeito preto-verde, no qual foi observado um incremento do número de compostos voláteis com o aumento do grau de torra. Porém, a concentração de cada composto deve ser considerada, pois efeitos de sinergismo entre os compostos contribuem para a formação do aroma final da bebida de café.

Foi observado um incremento da torra moderadamente escura para a escura das áreas dos seguintes CPs: 2-metilpirazina de 65; 111; 
2172 e $340 \%$ nas amostra preto C. canephora, preto C. arabica, pretoverde e PVA, respectivamente; e a piridina de 505, 120, 689 e 418\%, respectivamente. No entanto, o defeito verde não mostrou o mesmo comportamento dos demais defeitos, apresentando pequena diminuição percentual de ambos compostos. A quantidade de pirazinas depende da quantidade de aminoácidos e açúcares no sistema, ${ }^{21,26}$ que através de reações de Strecker e Maillard geram inúmeras pirazinas. Já as piridinas, além de serem oriundas destes tipos de reações, são também geradas pela degradação da trigonelina, que sofre intensa degradação durante o processo de torra. ${ }^{27,29}$ Isto sugere que no defeito verde tenha ocorrido a forte degradação de alguns compostos precursores de aroma logo no primeiro grau de torra (moderadamente escura), o que se refletiu na ausência de incremento das áreas dos compostos 2-metilpirazina e piridina na torra subseqüente. Tal suposição encontra-se de acordo com um estudo realizado em $2005,{ }^{13}$ que demonstra o comportamento diferenciado do defeito verde em relação aos defeitos preto e ardido e à amostra controle. Neste estudo, foi observado que na amostra torrada, o defeito verde apresentou níveis superiores de degradação da trigonelina (86\%) em relação aos demais defeitos. É possível que isto se deva à diferenciação da parede celular dos grãos defeituosos, devido ao grau de maturação destes, permitindo, através de permeabilidade, maior troca de calor durante a torração. Conseqüentemente, ocorre a aceleração do processo de degradação de inúmeros compostos voláteis.

\section{CONCLUSÕES}

Foi possível, através da análise de headspace, diferenciar os principais defeitos dos cafés crus e torrados. De forma geral, as classes de compostos voláteis observadas nos defeitos refletiram seus processos de formação e, portanto, confirmaram a hipótese de que é possível identificar compostos marcadores de defeitos específicos.

Neste estudo, os seguintes compostos foram característicos de defeitos específicos: 1-butanol, 3-metil-butanol e dodecanoato de metila no defeito verde cru, e 2-pentanona na torra moderadamente escura; 2-metilpropanal no defeito preto-verde cru, e 2,3-butanodiol no torrado; 1-pentanol, pentanal e 2-pentilfurano no defeito preto torrado.

Outros compostos foram observados somente nos grãos defeituosos em geral, como o 3-metilbutanal e o 2-metilbutanal nos defeitos crus; 1-hidroxi-2-butanona, 2-metilpropanal, hexanal, decanoato de etila e dodecanoato de etila, nos torrados.

Todavia, devido à complexidade da fração aromática do café, e ao fato desta ser dependente de técnicas agrícolas, cultivo, altitude, região, entre outras, um maior número de amostras de mesma origem deverá ser avaliado para a confirmação dos potenciais marcadores, bem como a identificação de novos compostos.

\section{AGRADECIMENTOS}

Ao Consórcio Brasileiro de Pesquisa e Desenvolvimento do Café (CBP\&DCafé-EMBRAPA) e ao Conselho Nacional de Pesquisa (CNPq - Brasil) pelo suporte financeiro; e à M. Pinto da Associação Brasileira das Indústrias do Café (ABIC) pelas informações técnicas fornecidas.

\section{REFERÊNCIAS}

1. http://www.portaldoagronegocio.com.br/index.php?idN=20267, acessada em Dezembro 2007.
2. http://www.abic.com.br/exportacao.html, acessada em Agosto 2007.

3. http://www.sindicafe-mg.com.br/pg2.asp?path=3_6, acessada em Dezembro 2007.

4. Toledo, J. L.; Barbosa, A. T.; Classificação e Degustação do Café, Sebrae: Rio de Janeiro, 1998.

5. Smith, A. W. Em Coffee Chemistry; Clarke, R. J.; Macrae, R., eds.; $1^{\text {st }}$ ed.; Elsevier Applied Science: London and New York, 1985, vol. 1, cap. 1.

6. Pimenta, C. J.; Qualidade de Café, $1^{\text {a }}$ ed.; UFLA: Lavras, 2003.

7. Bee, S.; Brando, C. H. J.; Brumen, G.; Carvalhaes, N.; Kolling-Speer, I.; Speer, K.; Liverani, F. S.; Teixeira, A. A.; Teixeira, R.; Thomaziello, R. A.; Viani, R.; Vitzthum, O. G. Em Espresso Coffee, The Science of Quality; Illy, A.; R. Viani, eds.; $2^{\text {nd }}$ ed.; Elsevier Academic Press: Italy, 2005, cap. 3.

8. Clarke, R. J. Em Coffee Chemistry; Clarke, R. J.; Macrae, R., eds.; $1^{\text {st }}$ ed.; Elsevier Applied Science: London and New York, 1987, vol. 2, cap. 2 .

9. Sampaio, A. L. P. Em Manual do Cafeicultor; Graner, E. A.; Godoy Jr., G., eds.; EDUSP: São Paulo, 1967.

10. Teixeira, A. A.; Hashizume, H.; Nobre, G. W.; Cortez, J. G.; Fazuoli, L. C.; Proceedings of the $10^{\text {th }}$ International Colloquium on the Chemistry of Coffee, Salvador, Brasil, 1982.

11. Teixeira, A. A.; Gomes, F. P.; Pereira, L. S.; Moraes, R. S.; Castilho, A. Em Boletim técnico $n^{\circ}$ 3; Ministério da Indústria e do Comércio - Inst. Brasileiro do Café, Depart. de Assistência à Cafeicultura, IBC: Rio de Janeiro, 1970.

12. Mazzafera, P.; Food Chem. 1999, 64, 547.

13. Franca, A. S.; Oliveira, L. S.; Mendonça, J. C. F.; Silva, X. A.; Food Chem. 2005, 90, 89.

14. Spadone, J. C.; Takeoka, G.; Liardon, R.; J. Agric. Food Chem. 1990, $38,227$.

15. Cantergiani, E.; Brevard, H.; Amado, R.; Krebs, Y.; Feria-Morales, A.; Yeretzian, C.; Proceedings of the $18^{\text {th }}$ International Colloquium on the Chemistry of Coffee, Helsinki, Finlândia, 1999.

16. Bortoli, G.; Fabian, M.; Proceedings of the $19^{\text {th }}$ International Colloquium on the Chemistry of Coffee, Trieste, Itália, 2001.

17. Guyot, B.; Cros, E.; Vincent, J. C.; Café Cacao Thé 1982, XXVI, 279.

18. Toci, A. T.; Farah, A.; Food Chem. 2008, 108, 1133.

19. http://www.abic.com.br/gar_qualidade.html, acessada em Dezembro 2007.

20. Menezes, H. C.; Leite, F.; Amstalden, L. C.; Ciênc. Tecnol. Aliment. 2001, 21, 123.

21. Dart, S. K.; Nursten, H. E. Em ref. 5, cap. 7.

22. Flament, I.; Coffee Flavor Chemistry; British Library Cataloguing in Publish Data: London, 2002.

23. Pittet, A. O.; Hruza, D. E.; J. Agric. Food Chem. 1974, 22, 264.

24. Clifford, M. N.; Wilson, K. C. Em Coffee Botany, Biochemistry and Production of Beans and Beverage, Clifford, M. N.; Wilson, K. C., eds.; $1^{\text {st }}$ ed.; Croom. Helm: London, 1985.

25. Czerny, M.; Mayer, F.; Grosch, W.; J. Agric. Food Chem. 1999, 47, 695.

26. De Maria, C. A. B.; Moreira, R. F. A.; Trugo, L. C.; Quim. Nova 1999, 22, 209.

27. Toci, A.; Farah, A.; Trugo, L. C.; Quim. Nova 2006, 29, 965.

28. Macrae, R.; Clarke, R. J. Em ref. 5, cap. 4.

29. Trugo, L. C.; Tese de Doutorado, University of Reading, Inglaterra, 1984. 